\title{
Study of the Effects of Slip Distance and Surface Roughness on Wear Rate
}

\author{
Milad Hadinezhad, Majid Elyasi", Mohammad Rajabi, Majid Abbasi \\ Faculty of Mechanical Engineering, Babol Noshirvani University of Technology, Iran
}

Copyright (C) 2015 by authors, all rights reserved. Authors agree that this article remains permanently open access under the terms of the Creative Commons Attribution License 4.0 International License

\begin{abstract}
The phenomenon of wear is one of the significant and reviewable topics in industrial parts and equipments. Furthermore, with the increasing expansion of rail transportation industry in the world, a noticeable part of researches in this area have been allocated to the study of wear between wheel and rail. The contact surfaces of wheel and rail in railway lines in particular intra-city lines (subway) are subject to intensive wear due to the creation of rolling motion. In current work, an experimental investigation was performed based on dry pin-on-disk test to find effects of slip distance, hardness and surface roughness on wear rate and plastic deformation in rail-wheel interfacial contact. Results indicated that the wear rate decreases by decrease in slip distance. Furthermore, it was observed that both wear rate and plastic deformation increases by increase in surface roughness of the wheel.
\end{abstract}

Keywords Slip Distance, Hardness Surface, Roughness, Wear Rate, Pin-on-disk Test

\section{Introduction}

Due to the specific importance of rail transportation in the world, the phenomenon of wear has converted into one of the noticeable topics in rail industry from the safety and economic perspectives $[1,2]$. The study of the phenomenon of wear leads to the proper design of suspension system and also the profile of optimal wheel [3].

The geometrical incompatibility of wheel profile with the geometrical features of a rail line can be followed by an intensive wear of wheel-rail, reduction of safety and dynamic instability of rail vehicle. On the other side, the dynamic instability causes the application of unrespectable periodical stress and forces on wheel at contact points which leads to the immature phenomenon of fatigue of contacts in wheels.

One of the important matters in wheel-rail contact is to determine the stresses resulting from interactions between wheel and rail. By specifying the geometry of contact area and determining the rate of stress and force parameters, it is possible to study the determinant parameters of wheel life such as wear and contact fatigue. Along with this, by optimizing the wheel and rail profile in order to reduce the stresses resulting from the wheel-rail interactive reactions, proper distribution of stress in contact area, using the wheel and rail two points contacts in direct lines and adjustment of contact angles, it will be possible to reduce the wear rate noticeably[4, 5].

In a poor lubricant condition, the wear can cause plastic deformation in interface of rail and wheel due to slipping-rolling interface [6]. In this situation, contact force, slip distance, lubrication, microstructure and hardness have great impact on the wear rate and subsequently on the plastic deformation $[7,8]$.

Ohyama et. al [9] in a test with two-disc machine in the condition of lubrication with water studied the effects of normal load on wear reduction and considered this trend of wear reduction with the increase of normal load as something connected with the coarseness of related surfaces. They showed that in the case of coarse free surfaces, the issue is opposite and with the increase of normal load, the wear will increase slightly [10].

\section{Simulation by ADAMS-RAIL}

In order to simulate the wear behavior between wheel and rail the ADAMS-RAIL commercial software has been utilized. In this software, the principle of contact between wheel and rail has been designed based on Kalker theory [11]. The main inputs for modeling of wear by ADAMS-RAIL are geometric model of train, mechanical behavior parameters such as springs and dampers, properties of rigid bodies, and shape characteristics of wheels and rails in contact places. The dynamical characteristics of train movement such as displacement, velocities and accelerates are obtained through dynamical analysis of train movement on railways. In the present work the ADAMS-RAIL software has been used to simulate wear phenomenon between wheels and rails. Table 1 , presents the input parameters which were entered in ADAMS-RAIL for simulation. 


\section{Experiments}

According to the range of laboratory wear-machine, it was decided to select slip distance and surface roughness as the main parameters. The corresponding ranges for these parameters were determined according to simulation in Adams Rail 2005 finite element software. In this simulation the lateral force was determined by moving the train in a curved path with zero inclined angles. The simulation was performed under two weights and velocities to obtain the lateral force. The forces then applied in pin-on-disk test experiments under dry lubricant condition. Table 1, presents the input parameters which were entered in ADAMS-RAIL for simulation. Also, Table 2 and 3 presents the slip distance and surface roughness factors and their corresponding levels.

Table 1. Input parameters for simulation

\begin{tabular}{|c|c|}
\hline Input parameters & Value \\
\hline Modulus of elasticity (GPa) & 210 \\
\hline Radius of path curvature (m) & 250 \\
\hline rolling radius (m) & 0.46 \\
\hline Wheelset base (m) & 2.56 \\
\hline Wagon length (m) & 24 \\
\hline Poisson's ratio & 0.3 \\
\hline Cant (rad) & 0 \\
\hline Wagon total weight (ton) & 42 \\
\hline Axle length (m) & 2 \\
\hline Wagon height (m) & 3 \\
\hline
\end{tabular}

Table 2. Input values of force, velocity and slip distance for wear test machine

\begin{tabular}{|c|c|c|c|}
\hline Test No & Force on $(\mathrm{N})$ & Velocity on $(\mathrm{m} / \mathrm{s})$ & Slip distance $(\mathrm{m})$ \\
\hline 1 & 46 & 0.6 & 1500 \\
\hline 2 & 46 & 0.6 & 3000 \\
\hline 3 & 46 & 0.6 & 4500 \\
\hline 4 & 46 & 0.6 & 6000 \\
\hline 5 & 64 & 0.9 & 1500 \\
\hline 6 & 64 & 0.9 & 3000 \\
\hline 7 & 64 & 0.9 & 4500 \\
\hline 8 & 64 & 0.9 & 6000 \\
\hline
\end{tabular}

Table 3. Input values of force, velocity and surface roughness for wear test machine

\begin{tabular}{|c|c|c|c|}
\hline Test No & $\begin{array}{c}\text { Force on } \\
(\mathrm{N})\end{array}$ & Velocity on $(\mathrm{m} / \mathrm{s})$ & $\begin{array}{c}\text { surface } \\
\text { roughness }(\mu \mathrm{m})\end{array}$ \\
\hline 1 & 46 & 0.6 & 1 \\
\hline 2 & 46 & 0.6 & 3 \\
\hline 3 & 46 & 0.6 & 7 \\
\hline 4 & 64 & 0.9 & 1 \\
\hline 5 & 64 & 0.9 & 3 \\
\hline 6 & 64 & 0.9 & 7 \\
\hline
\end{tabular}

In order to perform pin-on-disk test, the wheels and rails were prepared from R7 and 900A standards, respectively. Table 4 present the chemical compositions and mechanical properties of specimens. The pin had same material with rail, and the disk was prepared based on the wheel material [12]. Both pin and disk were prepared by means of universal turning machine, as shown in Fig. 1 and 2.

During the test, the surface roughness of both pin and disk was equal. The pin was polished with the paper by grade of 600 . Also, the disk surface was ground by means of magnetic grinding machine. After finishing the surface roughness of both pin and disk were equal to $3 \mu \mathrm{m}$.

Figure 3 shows the Pin-on-disk wear machine test. The device is equipped with a pneumatic system that controls the vertical force. It also had two load cells. Vertical force by force meter embedded inside the cylinder and the frictional force was measured by load cell. Pin specimen by a three-disk system is automatic and torque on the motor shaft, which is responsible for the rotation of the disk was placed.

All variables tested by the computer unit connected to the device, be controlled. Through device software, variables such as vertical load, linear speed, disc diameter and the number of times the disk was adjusted to distance the input system. The output variable as well as variables such as temperature and friction of software was visible.

Table 4. Chemical composition of rail and wheel used in this research

\begin{tabular}{|c|c|c|c|c|c|c|}
\hline Material & $\begin{array}{c}\text { Tensile } \\
\text { strength }(\mathrm{MPa})\end{array}$ & $\begin{array}{c}\text { Hardness } \\
(\mathrm{HV})\end{array}$ & $\% \mathrm{C}$ & $\% \mathrm{Si}$ & $\% \mathrm{Mn}$ & $\% \mathrm{Cr}$ \\
\hline Wheel & 880 & 260 & 0.55 & 0.4 & 0.8 & 0.3 \\
\hline Rail & 950 & 267 & 0.7 & 0.3 & 1 & 0.3 \\
\hline
\end{tabular}

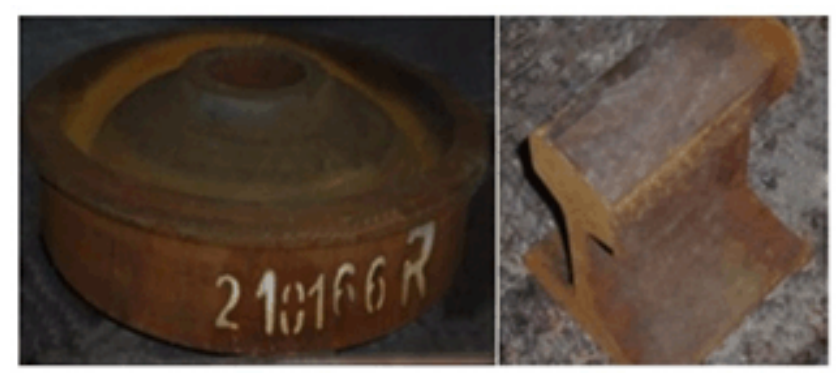

Figure 1. The used type of rail and wheel in this research
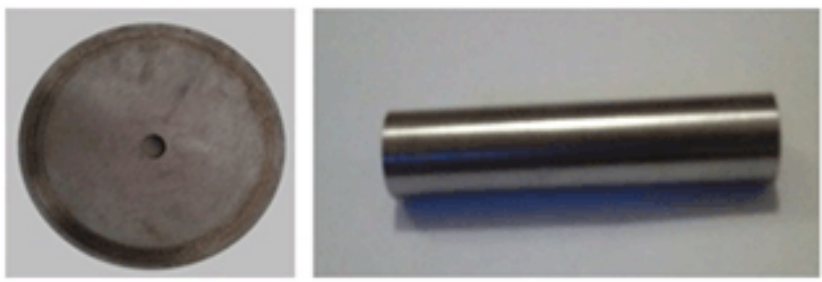

Figure 2. The prepared pin and disk for test

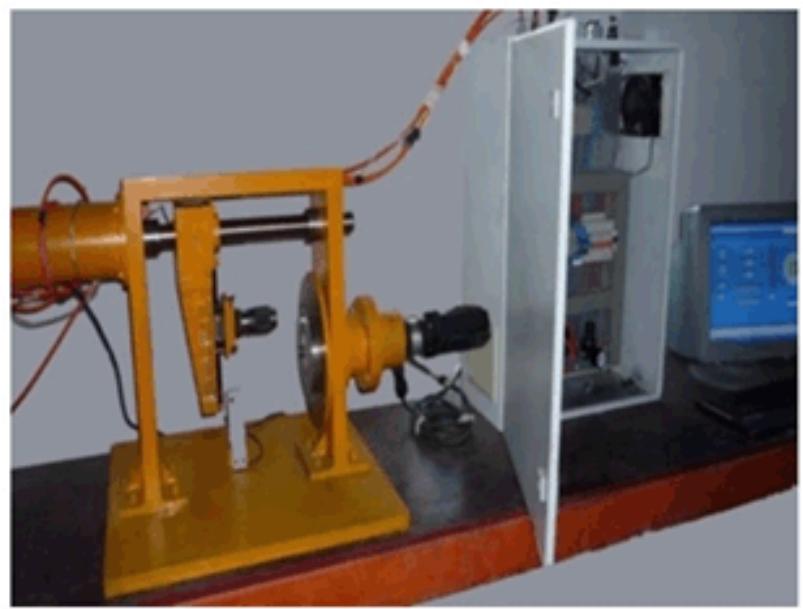

Figure 3. The Pin-on-disk wear machine test 
The pin-on-disk test is a standard test to analyze wear strength or wear rate of contacts. The tests were carried out with in a disk and different pins. After performing experiments the specimens were weighed by means of a digital balance with $0.0001 \mathrm{~g}$ resolution. Then their mass reductions were recorded to calculate the wear rate using following equation.

$$
\left(W_{1}-W_{2}\right) / S=\text { Wear rate }
$$

Where, $W_{l}$ is the specimen's weight before experiment and $W_{2}$ is the specimen's weight after experiment. Also, $S$ is the slip distance. The $\mathrm{S}$ is equal to $1500 \mathrm{~m}$ in all experiments.

In order to find effects of slip distance and surface roughness $\mathrm{n}$ wear rate, these factors varied over their available ranges while the other parameters were kept constant. Tables 4 and 5 present the experiments which were designed to analyze effects of slip distance and surface roughness respectively.

To analyze effects of process parameter on plastic deformation and wear mechanism a stereo microscope along with scanning electron microscope were utilized. The taken images provide beneficial information about worn surface topography and wear mechanism during motion.

\section{Effect of Slip Distance on Wear Rate}

Figures 4 and 5 show the effects of slip distance on mass variation and wear rate, respectively. From these figures it is evident that by increase in slip distance the mass reduces correspondingly while the wear rate decreases. In other word, the wear increases by increase in slip distance, but the wear rate decreases due to higher slip distance. According to Fig. 5 by increase in slip distance the wear rate decreases and tends to be linear.

Fig. 6 presents the hardness of the surface during the process. It is seen from the figure that the hardness of the surface increases by the time. This is due to work hardening effect that causes harder surface that being strong against wear [13]. Also Archard [14] introduces the adhesive wear mechanism as follows:

$$
\mathrm{W}_{\mathrm{ad}}=\mathrm{V} / \mathrm{L}=\mathrm{K}\left(\mathrm{F}_{\mathrm{n}} / \mathrm{H}\right)
$$

Where $\mathrm{W}_{\mathrm{ad}}$ is wear rate (the volume of rail and wheel mass loss during slip distance), $\mathrm{K}$ is wear coefficient, $\mathrm{V}$ is Velocity, $\mathrm{L}$ is slip distance, $\mathrm{F}_{\mathrm{n}}$ is normal force and $\mathrm{H}$ is hardness of softer material.

The main weakness of Archard model was considering to hardness as main component of his equation. Hence, in further study Hornbogen [15] modified the Archard's model as following Eq. (3).

$$
\mathrm{W}_{\mathrm{ad}}=\mathrm{N}^{2}\left(\mathrm{P}_{\mathrm{y}} \cdot \mathrm{E} \cdot \mathrm{F}^{1.5}{ }_{\mathrm{n}}\right) /\left(\mathrm{k}_{\mathrm{IC}}^{2} \cdot \mathrm{H}^{1.5}\right)
$$

Where $\mathrm{K}_{\mathrm{Ic}}$ is the material's fracture toughness, $\mathrm{P}_{\mathrm{y}}$ is yield stress of softer surface, $\mathrm{E}$ is combinational modulus of elasticity for both surfaces, $\mathrm{H}$ is hardness of softer material, $\mathrm{F}_{\mathrm{n}}$ is normal force and $\mathrm{N}$ is work hardening factor.

As relations (2) and (3) occurs, the effect of hardness on the wear rate of wear is one of the main parameters, it is seen that the wear rate decrease by increase in the hardness.

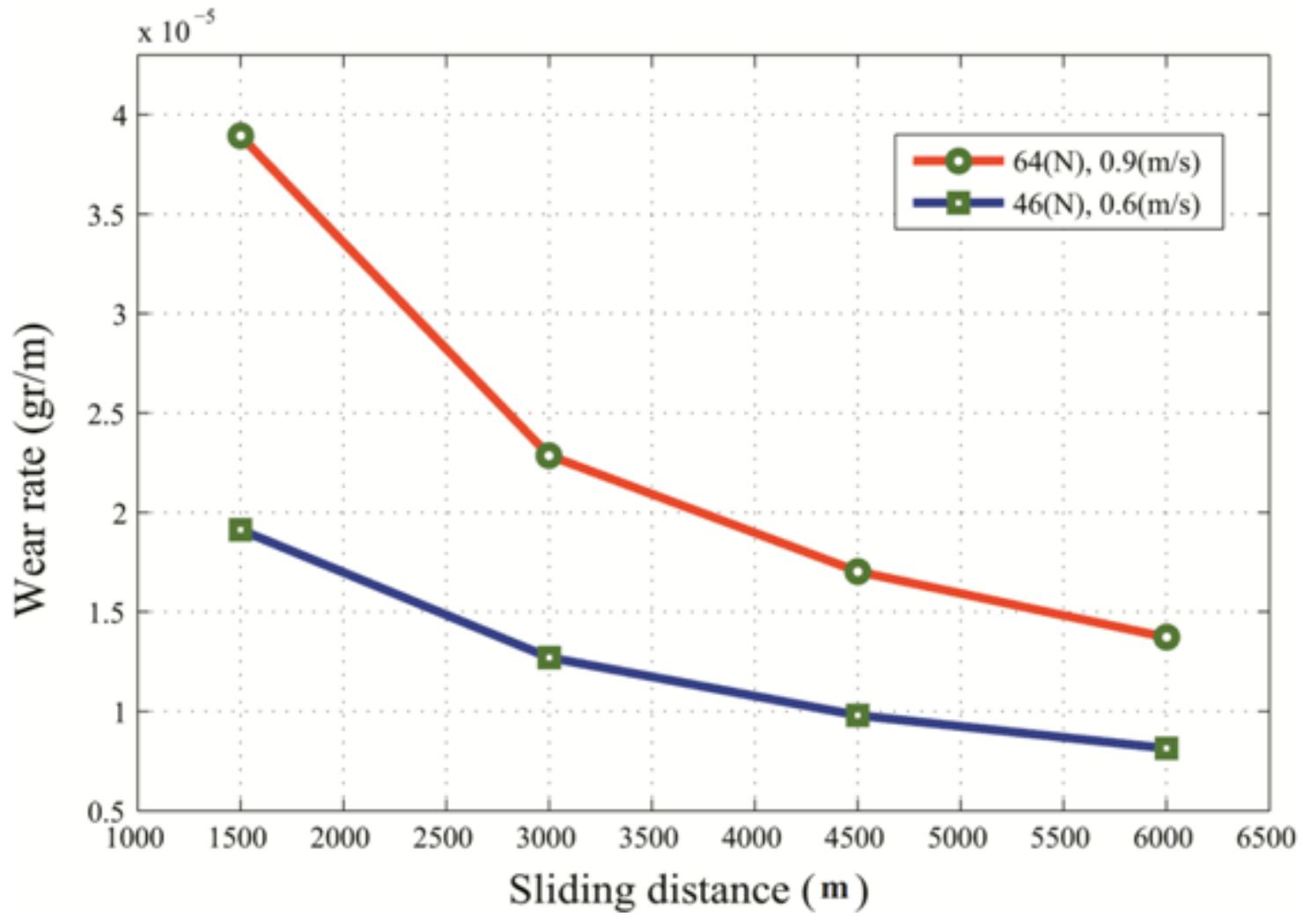

Figure 4. Variation of wear rate according to sliding distance 


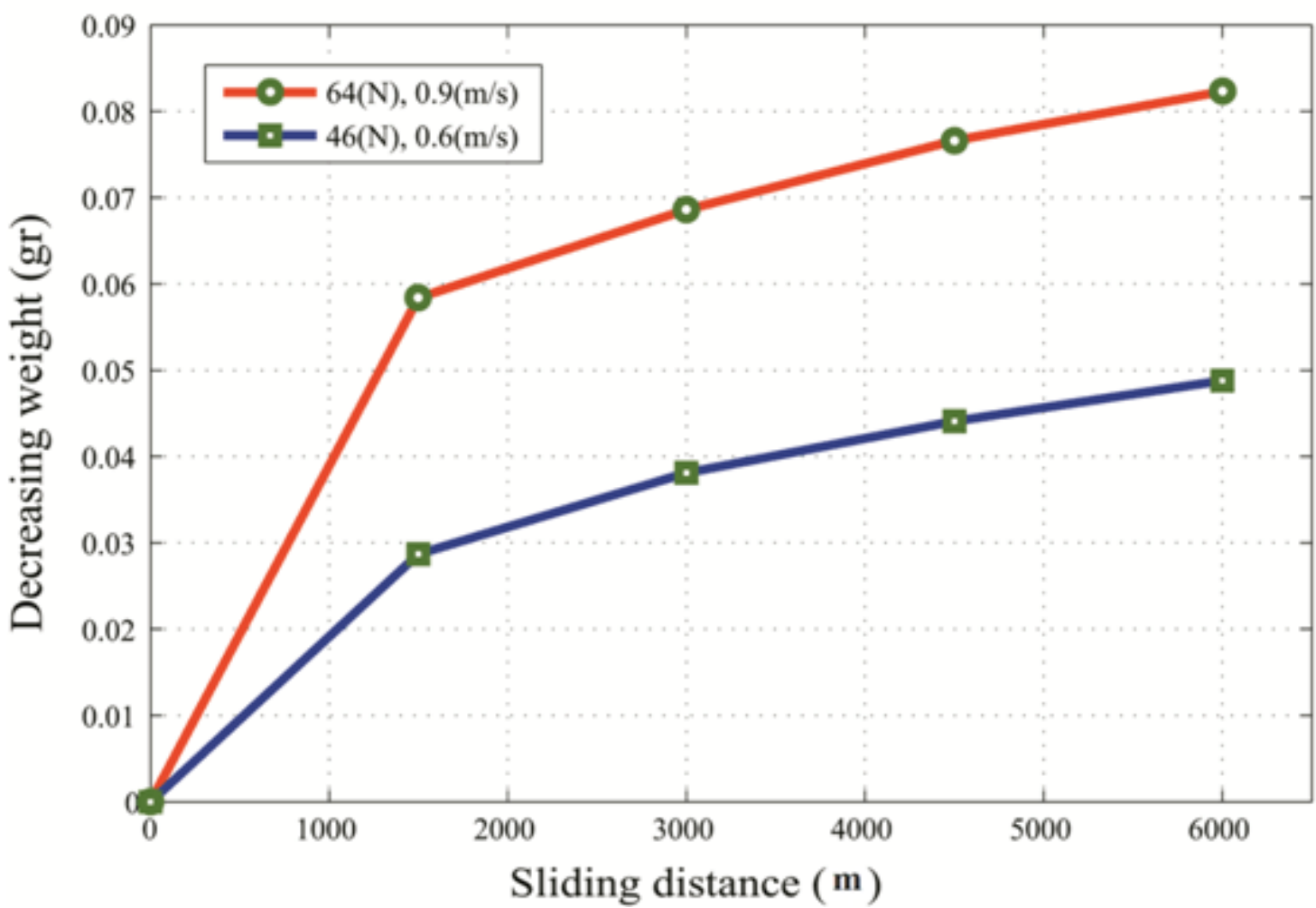

Figure 5. Variation of decreasing weight according to sliding distance

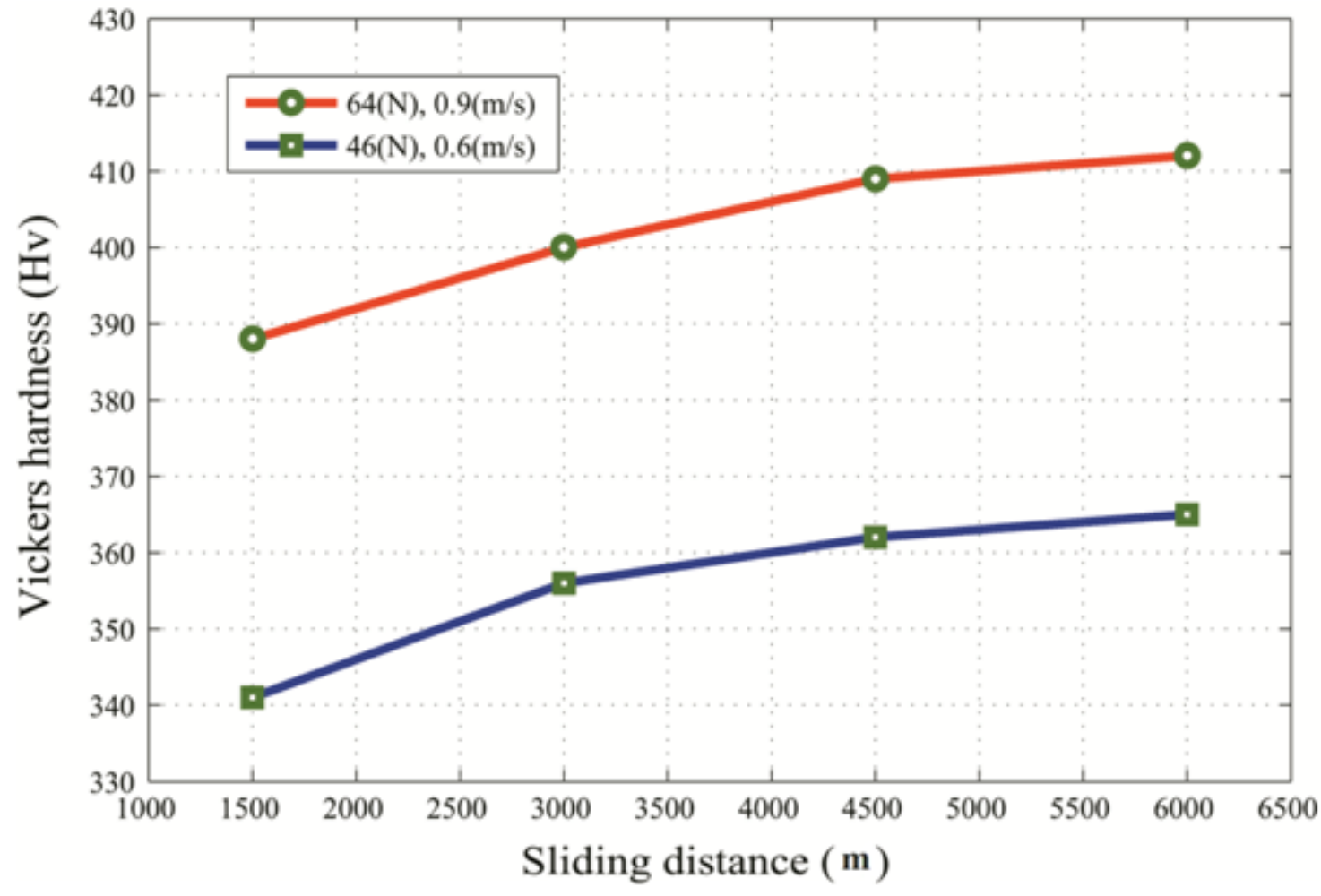

Figure 6. Variation of hardness according to sliding distance 


\section{Microscopic Analysis on Effect of Slip Distance on Plastic Deformation and Wear}

Fig. 7 reveals the surface images under various slip distances. Fig. 7(a) demonstrates the pin surface under $1500 \mathrm{~m}$ slip distance. According to this figure, it is seen that the craters are formed on the surface due to sticking a rigid body into softer material. Fig. 7(b) and 7(c) reveal the surface image under 3000m and 4000m slip distance, respectively. Due to higher slip distance, the formed craters become deeper. Also, due to temperature rise in the interface surface the plastic deformation became easier and material flow filled the formed craters.

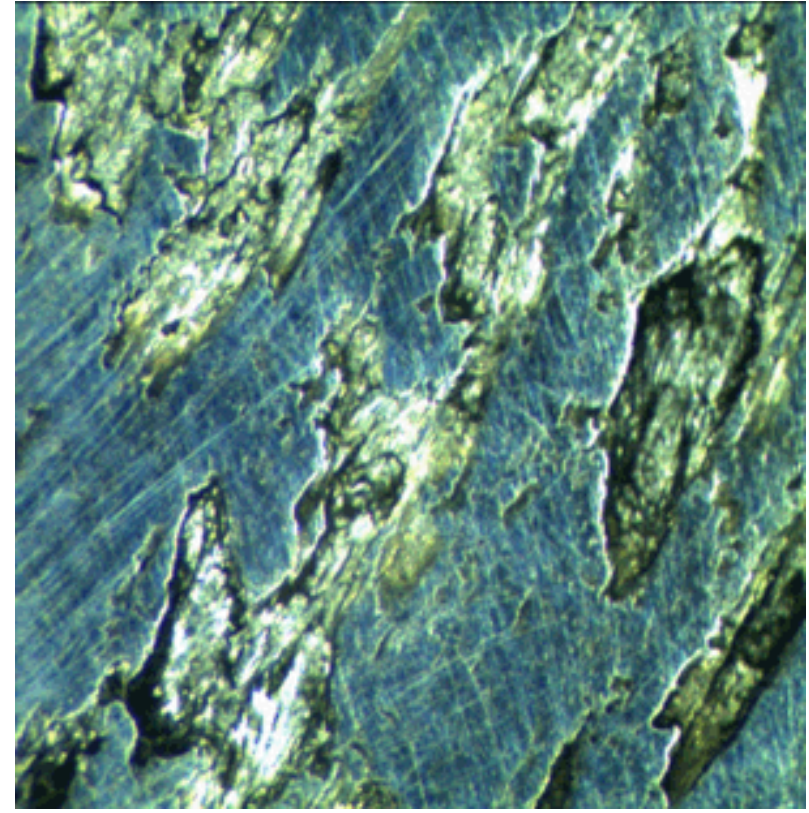

(a)

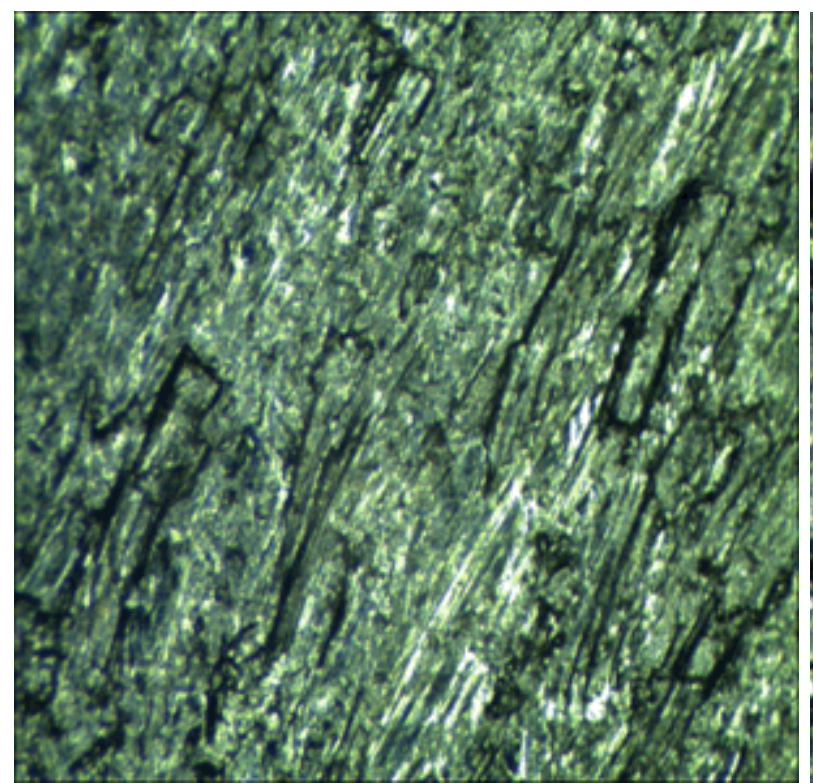

(c)

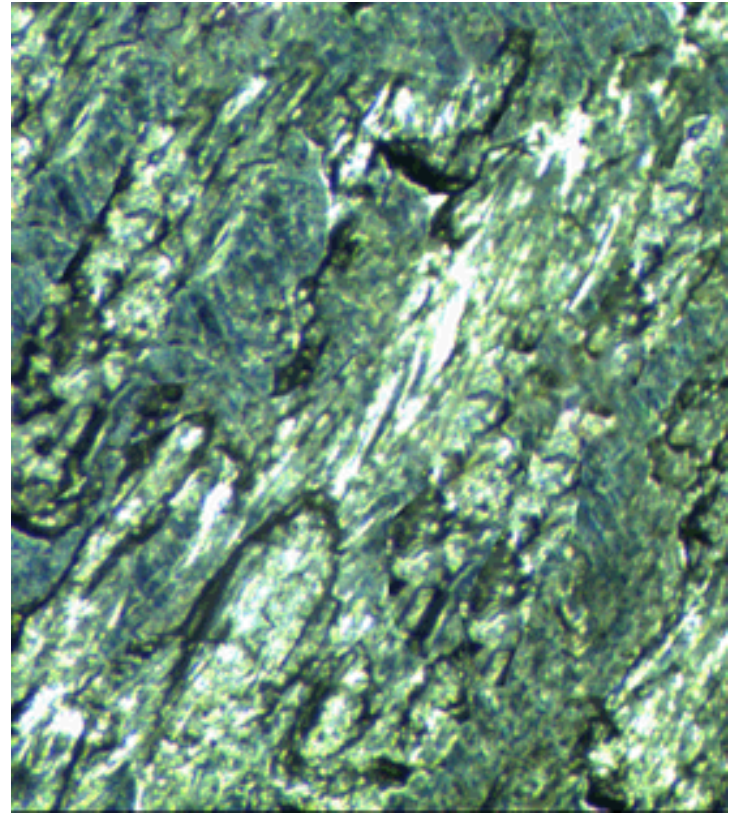

(b)

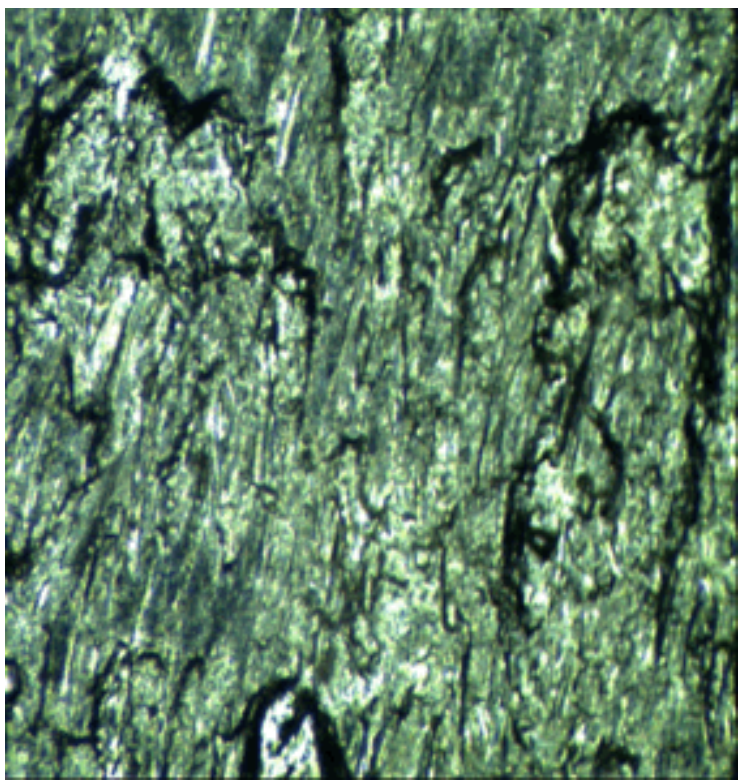

(d) 


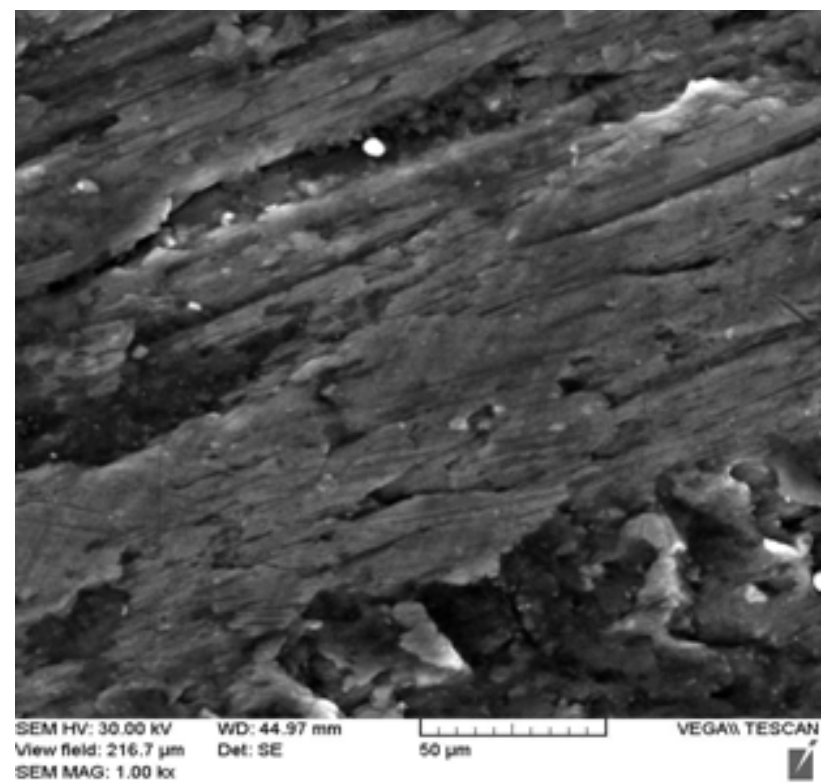

(e)

Figure 7. Optical microscopy image of worn surface at slip distances (a) $1500 \mathrm{~m}$, (b) $3000 \mathrm{~m}$, (c) $4000 \mathrm{~m}$, (d) and (e) $6000 \mathrm{~m}$
Fig. 7(d) and 7(e) indicates the surface image under $6500 \mathrm{~m}$ slip distance. According to the figures, at high slip distance, the interface surface becomes rougher and the topography of the surface looks like a rock shape. In such a condition the materials firstly departed from the surface and then stick on it. High temperature in the interface causes material flow and the surfaces are mixed together. Therefore, an adherent friction condition damages the surfaces of pin and disk and increases the wear rate.

\section{Effect of Surface Roughness}

Fig. 8 illustrates effects of surface roughness on wear rate. in this figure, it is seen that the wear rate increases by increase in surface roughness of contacts. When the surface roughness is $1 \mu \mathrm{m}$, the wear rate is about $0.5 \times 10^{-5}$ and by increase in surface roughness to $3 \mu \mathrm{m}$ the wear rate increases to $3.8 \times 10^{-5}$. However, at higher surface roughness value (i.e. $7 \mu \mathrm{m})$ this effect is saturated. It means that at $7 \mu \mathrm{m}$ surface roughness the wear rate is $4.4 \times 10^{-5}$.

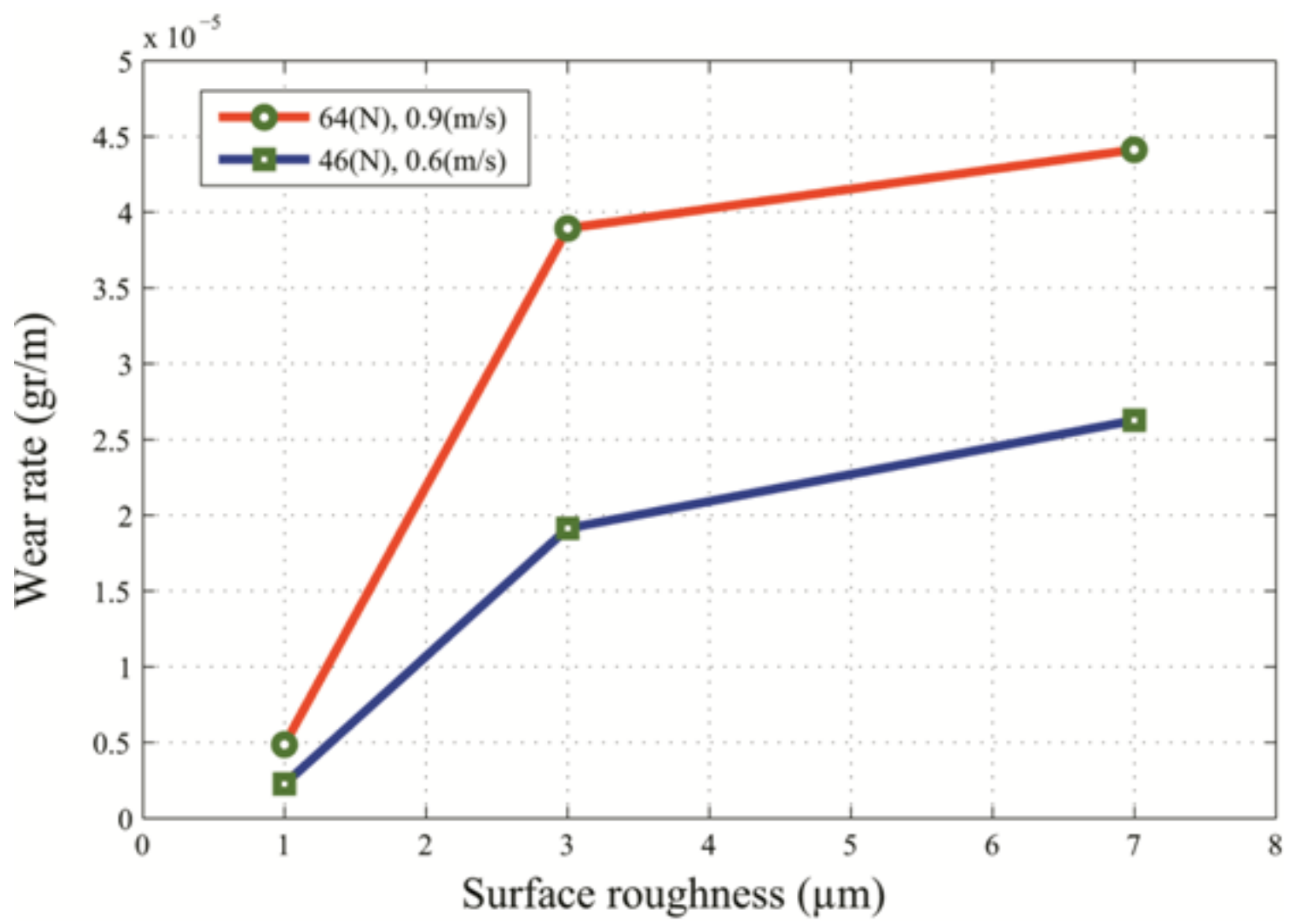

Figure 8. Variation of wear rate according to surface roughness 


\section{Microscopic Analysis on Effect of Surface Roughness on Plastic Deformation and Wear}

Fig. 13 illustrates the image surface under various surface roughnesses. Fig. 9(a) presents the pin surface under $1 \mu \mathrm{m}$ surface roughness. According to this figure due to high surface quality, it isn't seen sever damages on pin surface. In such situation the rigid body cannot stick into softer material easily. Because of slip motion the wear mechanism is adhesion and tends to change to adherent mechanism. Fig. 9(b) demonstrates the pin surface under $3 \mu \mathrm{m}$ surface roughness. According to this figure the crater formed on pin surface that implies sever plastic deformation in interface. This is due to increasing in contact area at higher roughness value. By increase in surface roughness, the surface layers of each contact welded together and ruptured at specific deep. In such situation the wear mechanism is adherent and causes increase in crack density and voids on the surfaces. Figures 9(c) and 9(d), presents the worn surfaces on $7 \mu \mathrm{m}$ surface roughness. In such a condition, the ruptured materials from the surface are further but these materials adhered to surface when the temperatures rise. At higher interface between the surfaces (at high surface roughness value) the work hardening increases and causes the wear rate occurs with fatigue mechanism. This mechanism is due to oscillation of contact stresses between two surfaces. Although under this mechanism the wear is saturated to some extent, it leads to the growth of cracks in beneath surfaces of contacts.

From contact mechanic point of view, the wear is unavoidable phenomenon with occurs with adherent mechanism majorly. This mechanism occurs due to the plastic deformation of surface dendrites and layers under high localized stress [16]. In this condition, the worn surfaces suffer higher plastic deformation rather than non-worn surfaces. Due to loading in the interface, crystalloid motion within the materials starts on the reverse directions and causes a sever lock in material flow [17]. By further contact between the surfaces the residual stresses occur in the pin and disk and materials become plastic hardened. In such situation, due to plastic strain the fatigue life decreases.

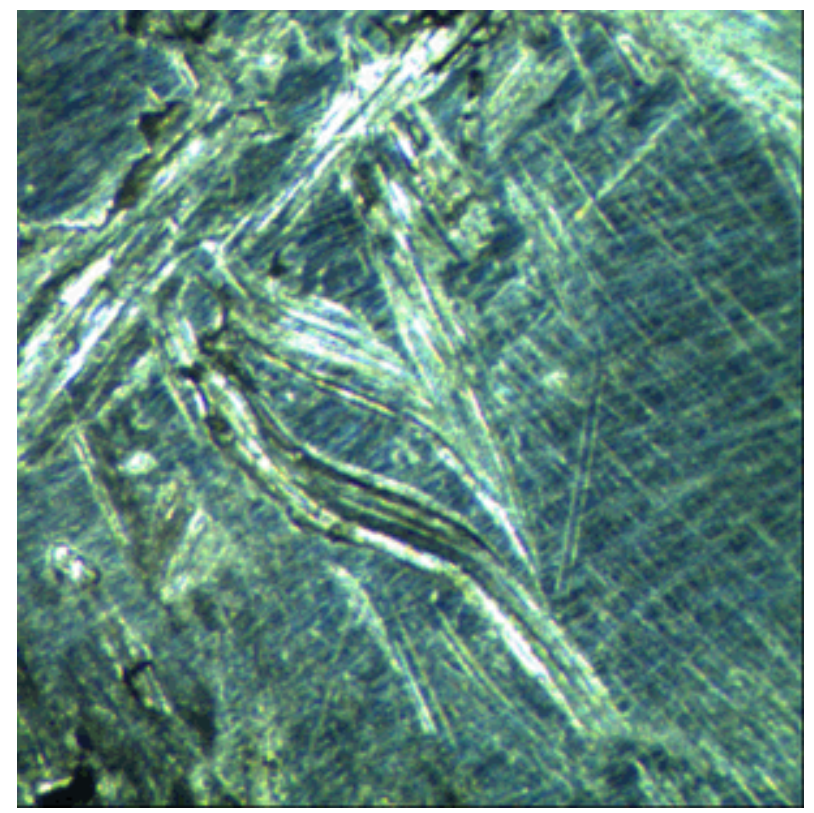

(a)

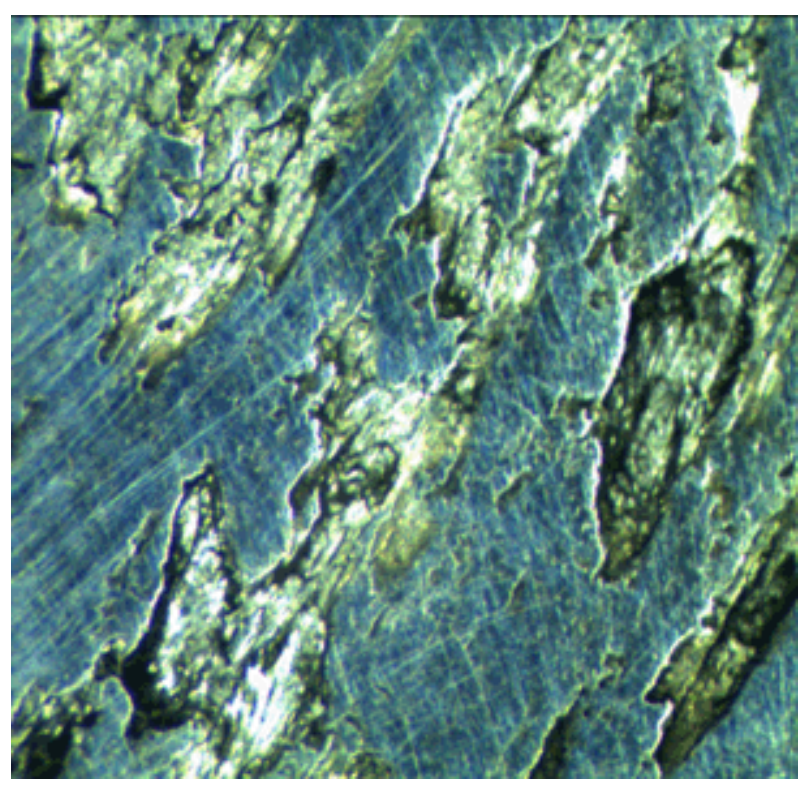

(b) 


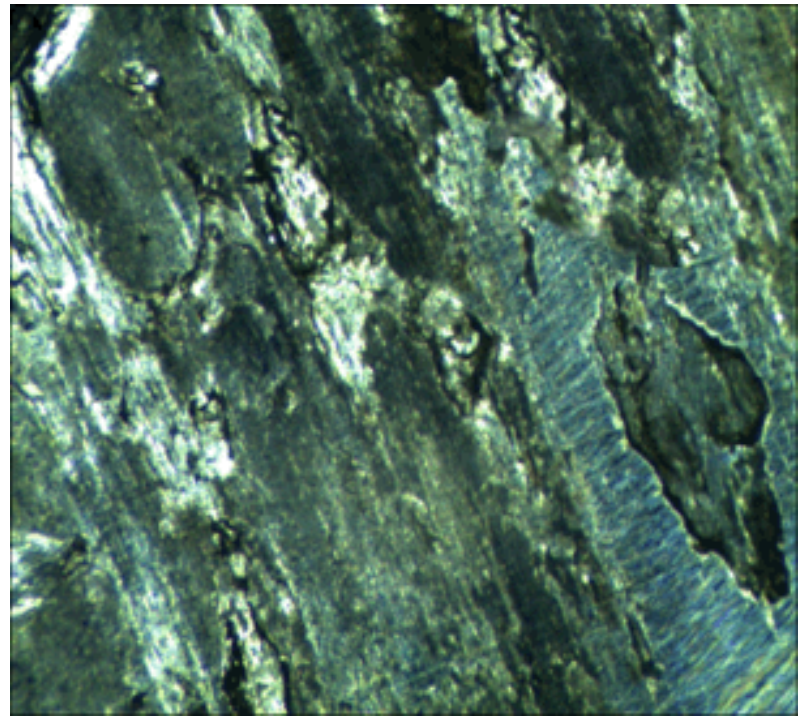

(c)

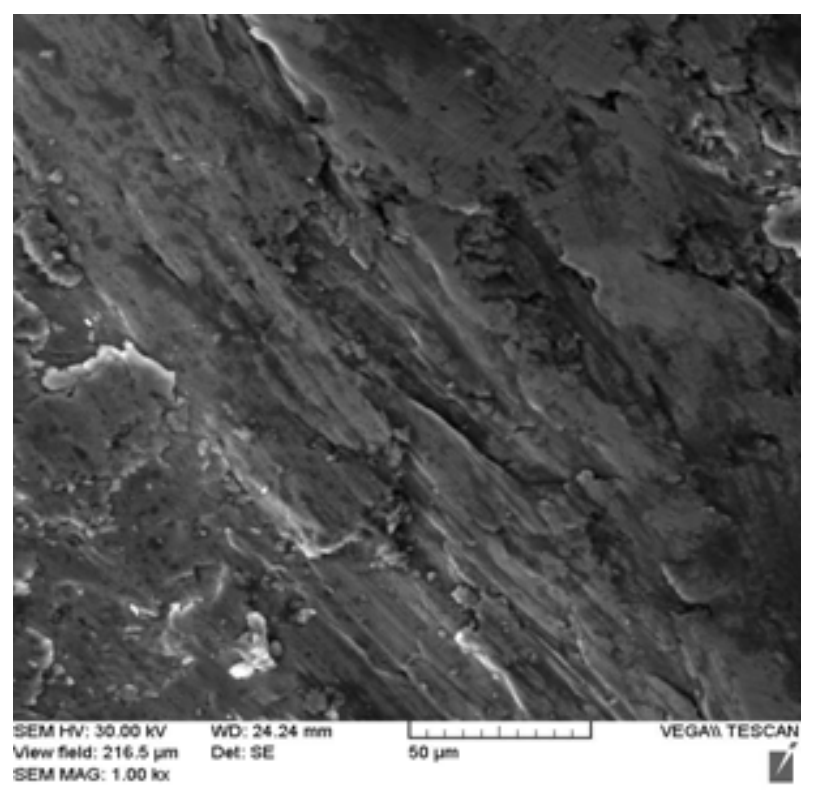

(d)

Figure 9. Optical microscopy image of worn surface at surface roughness (a) $1 \mu \mathrm{m}$, (b) $3 \mu \mathrm{m}$, (c)and(d) $7 \mu \mathrm{m}$

\section{Conclusions}

In this paper effects of slip distance, hardness and surface roughness were analyzed on plastic deformation and the wear mechanism. The obtained results are summarized as follows

1. By increase in slip distance the wear increase, but the wear rate decreases because the wear rate has an inverse relation with the wear rate.

2. By increase in slip distance, the materials become strain hardened in their interface. In such condition the surface hardness increases and protects the surface from further wear.
3. By increase in surface roughness, the wear rate increases. It is observed that when the surface roughness increases from $1 \mu \mathrm{m}$ to $3 \mu \mathrm{m}$, the wear rate increases eight times further.

4. The wear under dry condition is due to high stress in the interface and causes temperature rise and plastic deformation. By continuing the contacts, the pin and disk adhered and ruptured together that cause removing materials from both of them. in such a condition adherent wear mechanism causes severe plastic deformation of surface layers. Here, the worn surface suffers a high degree of plastic deformation than the non-worn surface.

\section{Acknowledgements}

The authors would like to express our sincere thanks to respectable mangers of Tehran subway in particular $\mathrm{Mr}$. Shahbazi and Mr. Aminzadeh for their cooperation in presenting experimental data to the authors.

\section{REFERENCES}

[1] A. Falahati, A. Hosainabadi, Study of the effect of process parameters on wear, International Conference on Recent Advances in Rail way Engineering, (2009), in Persian.

[2] Y. Salami, B. Serajian, Study of the stress of wheel and rail by using FEM, International Conference on Recent Advances in Rail way Engineering, (2009), in Persian.

[3] T. Jendel, Prediction of wheel profile wear-comparisons with field measurements, Wear, 253 (2002) 89-99.

[4] International Heavy Haul Association., Book: Guidelines to best practices for heavy haul railway operations: wheel and rail interface ISSUES .(2001)

[5] M. Pau, F. Aymerich, F. Ginesu "Distribution of contact pressure in wheel-rail contact area" Wear 253, 265-274, (2002).

[6] U. Olofsson, S. Andersson, S. Björklund, " Simulation of mild wear in boundary lubricated spherical roller thrust bearings", Wear 241, 180-185, (2000).

[7] J.E. Garnham, J.H. Beynon, “ Dry rolling-sliding wear of bainitic and pearlitic steels”, Wear 157, 81-109, (1992).

[8] H. Muster, H. Schmedders, K. Wick, H. Pradier, “ Rail rolling contact fatigue: the performance of naturally hard and head-hardened rails in track", Wear 191 54-64. (1996).

[9] T. Ohyama, H. Maruyama, Traction slip at higher rolling speeds: some experiments under dry friction and water lubrication, Mechanics and Wear of Rail/Wheel Systems, 1 (1982) 395- 418 .

[10] K.S. Baek, K. Kyogoku, T. Nakahara, An experimental study of transient traction characteristics between rail and wheel under low slip and low speed conditions, Wear, 271 (2008) 100-113. 
[11] J. A. Greenwood, J.B. Williamson, Contact of nominally flat surfaces, Proc. r. soc. lond, 295 (1966) 300-319.

[12] R.E. Smith, J. Kalousek, A design methodology for wheel and rail profiles for use on steered railway vehicles, Mechanics and Fatigue in Wheel/Rail Contact, 1 (1990) 329-342.

[13] Ki Myung Lee; Andreas A; Polycarpou "Wear of conventional pearlitic and improved bainitic rail steels". Wear 259, pp 391-399. , (2005).
[14] Archard,J.F., "Contact and rubbi ng of flat surfaces" , Journal of applied physics, Vol.24, PP.98 (1953).

[15] Bhushan,B., “ Tribology and mechanics of magnetic storage devices”, Springer Verlag, New York, 1990

[16] Ludger Deters; Ma thias Proksch "Friction and wear testing of rail and wheel material”. Wear 258, pp. 981-991. (2005)

[17] Ying Jin, Makoto Ishida, "Experimental simulation and prediction of wear of wheel flange and rail gauge corner", Wear 271, 259-267, Japan(2011). 